\title{
RANCANG BANGUN INFRASTRUKTUR JARINGAN HOTSPOT BERBASIS VOUCHER MENGGUNAKAN METODE PCQ
}

\author{
Givy Devira Ramady ${ }^{1)}$, Andrew Ghea Mahardika ${ }^{2)}$, Syafruddin $^{3)}$ \\ ${ }^{1,2,3)}$ Teknik Elektro Sekolah Tinggi Teknologi Mandala \\ Soekarno-Hatta St No.543, Gumuruh, Batununggal, Kota Bandung, Jawa Barat \\ e-mail: givy.d.ramady@gmail.com ${ }^{1)}$, andrewhinata@gmail.com ${ }^{2}$, syafruddinr@yahoo.com ${ }^{3)}$
}

\begin{abstract}
ABSTRAK
Teknologi wireless saat ini telah menjadi pilihan yang banyak digunakan dalam pengembangan teknologi informasi dan komunikasi. Ketersediaan fasilitas layanan komunikasi data internet dalam mendukung mobilitas di lingkungan kampus seperti browsing, mengunduh dan mengunggah data memberikan kemudahan bagi setiap user untuk dapat mengakses layanan tersebut dengan hanya menghubungkan perangkat mobile ke dalam jaringan tersebut. Agar kualitas layanan komunikasi data internet selalu berada dalam kondisi yang optimal, maka perlu diperhatikan di awal mengenai desain, topologi, serta perangkat yang akan digunakan pada infrastruktur jaringan yang akan dibangun. Selain persiapan terhadap infrastruktur fisik jaringan, upaya peningkatan performa berupa implementasi sistem monitoring serta manajemen jaringan berupa quality of service $(Q o S)$ merupakan sebuah langkah penting yang tidak dapat dikesampingkan. Implementasi QoS pada sebuah jaringan hotspot yang bertindak sebagai pembagi bandwidth sehingga proses distribusi layanan komunikasi data internet mampu secara merata diterima oleh setiap user yang terhubung. Metode peer connection queue (PCQ) yang digunakan bertujuan untuk memastikan agar setiap user dapat menerima kualitas layanan sesuai dengan jenis paket data yang digunakan. Ada beberapa jenis paket data yang diterapkan, diantaranya paket gold, silver, dan bronze yang mana setiap paket tersebut memiliki perbedaan pada besaran bandwidth yang diterima serta batasan terhadap akses web tertentu. Pengujian performa jaringan dilakukan dengan cara memonitoring besaran bandwidth pada masing-masing paket pada saat sebelum dan sesudah penerapan metode $P C Q$.
\end{abstract}

Kata Kunci: bandwidth, hotspot, internet, jaringan

\begin{abstract}
Wireless technology has become the most widely used choice in the development of information and communication technology. The availability of internet data communication service facilities in support of mobility in the campus environment such as browsing, downloading and uploading data makes it easy for every user to be able to access the service by simply connecting his mobile device to the network. So that the quality of internet data communication services is always in optimal conditions, it is necessary to pay attention in advance regarding the design, topology, and devices that will be used in the network infrastructure to be built. In addition to the preparation of the physical network infrastructure, efforts to improve performance in the form of implementing a monitoring system and network management in the form of quality of service (QoS) is an important step that cannot be ruled out. The implementation of QoS on a hotspot network acts as a bandwidth divider so that the process of distribution of internet data communication services is able to be evenly accepted by every connected user. The peer connection queue (PCQ) method used aims to ensure that each user can receive service quality in accordance with the data packet cluster used. There are several data packet clusters that are implemented including gold, silver, and bronze packages, where the difference between the three is in the amount of bandwidth received and limitations on web access. Network performance testing is done by looking at the value of bandwidth before and after applying the PCQ method.
\end{abstract}

Keywords: bandwidth, hotspots, internet, networks

\section{PENDAhUluan}

$\mathrm{T}$ leknologi wireless saat ini telah menjadi pilihan yang banyak digunakan dalam pengembangan teknologi informasi dan komunikasi. Kemudahan akses serta mobilitas tinggi yang dimiliki jaringan wireless, membuatnya menjadi pilihan utama pada saat membangun sebuah infrastruktur jaringan. Bentuk implementasi teknologi jaringan wireless salah satunya berupa pemasangan titik hotspot di pusat perbelanjaan, sekolah, serta ruang terbuka publik lainnya. Titik hotspot ini memungkinkan seorang pengguna untuk dapat terhubung kedalam sebuah jaringan komunikasi data internet selama berada didalam jangkauan area titik hotspot tersebut. Agar kualitas layanan komunikasi data internet selalu berada dalam kondisi yang optimal, maka perlu adanya perawatan serta monitoring secara berkala yang dilakukan terhadap sistem jaringan.

Implementasi quality of service $(Q o S)$ pada sebuah jaringan hotspot bertindak sebagai pengatur bandwidth, sehingga proses distribusi layanan komunikasi data internet dapat secara merata diterima oleh setiap user yang terhubung. Hal ini dilakukan untuk mencegah pemakaian bandwidth secara berlebih oleh user[1]. Pemakaian 
bandwidth yang berlebih akan menyebabkan kualitas layanan jaringan menurun sehingga akan mengganggu stabilitas koneksi user yang lainnya.

Pada sebuah jaringan yang memiliki banyak user, terkadang akan muncul permasalahan berupa kecepatan koneksi internet yang tidak stabil yang salah satunya merupakan dampak dari banyaknya user yang aktif secara bersamaan. Untuk itu maka diperlukan sebuah mekanisme pengaturan bandwidth yang bertujuan untuk mencegah terjadinya ketidakmerataan bandwidth. Metode peer connection queue (PCQ) digunakan untuk memastikan setiap user dapat menerima bandwidth yang sesuai dengan tipe paket data yang dipilih. Ada beberapa tipe paket data yang ditawarkan melalui sistem yaitu paket gold, silver, dan bronze. Perbedaan pada masing-masing paket tersebut berupa limitasi kecepatan koneksi data serta hak akses terhadap beberapa layanan[2].

Dalam penelitian[3], dilakukan upaya optimalisasi jaringan berbasis wireless menggunakan teknik wireless distribution system (WDS ). Pada penelitian tersebut performa jaringan yang menggunakan teknik WDS naik secara cukup signifikan meskipun teknik WDS memiliki sebuah kelemahan yaitu performanya akan sedikit menurun bila digunakan pada area yang terlalu luas. Kemudian pada [4], [5], dilakukan uji terhadap beberapa metode pada router mikrotik selain $P C Q$. Perancangan infrastruktur yang baik dapat meningkatkan kualitas layanan data internet sehingga dapat mengoptimalkan kinerja dari sistem yang memanfaatkannya[6], [7], [8].

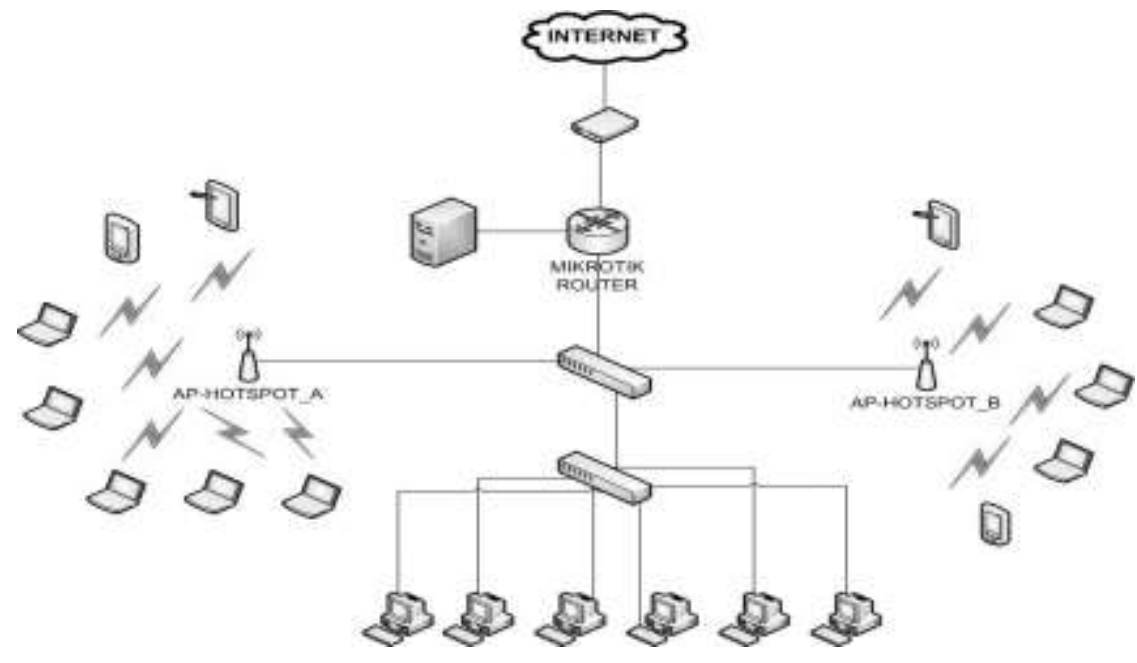

Gambar 1. Skema desain infrastruktur jaringan

\section{TINJAUAN PUSTAKA}

\section{A. Topologi}

Topologi jaringan adalah sebuah mekanisme yang digunakan dalam merangkai sebuah sistem jaringan komputer berbasiskan kabel ataupun wireless. Ada beberapa topologi yang umum digunakan saat ini dan penerapannya dapat disesuaikan berdasarkan desain jaringan serta skala penggunanya. Topologi tersebut diantaranya topologi tree, star, mesh, tree, ring, dan bus.

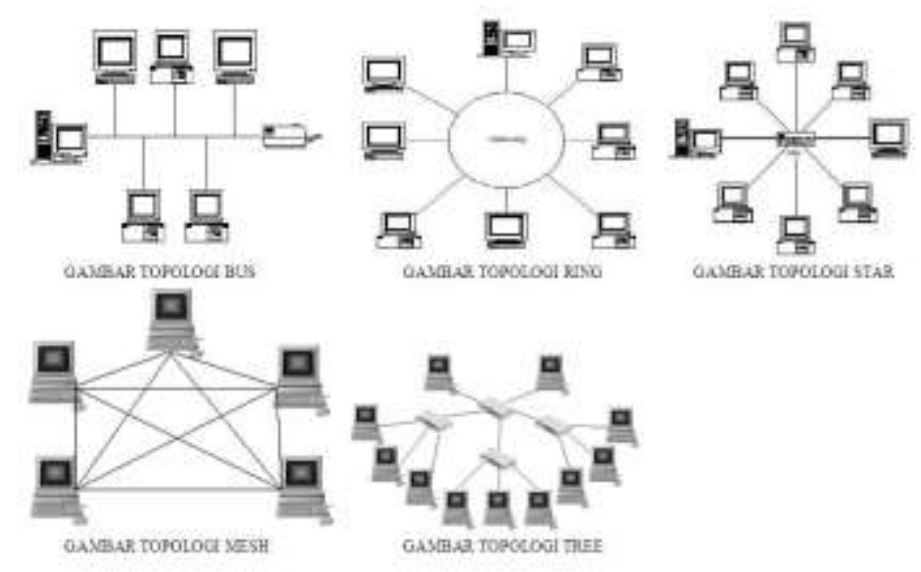

Gambar 2. Topologi Jaringan 


\section{B. Peer Connection Queue (PCQ)}

$P C Q$ merupakan sebuah metode dalam manajemen bandwidth yang bekerja dengan menggunakan sebuah algoritma yang akan membagi bandwidth secara merata ke sejumlah client yang aktif. $P C Q$ biasa digunakan bila admin kesulitan dalam menghadapi jumlah client/user yang terlalu banyak. Dengan menggunakan metode $P C Q$, proses pembagian bandwidth akan dilakukan secara otomatis berdasarkan jumlah user/client yang aktif.

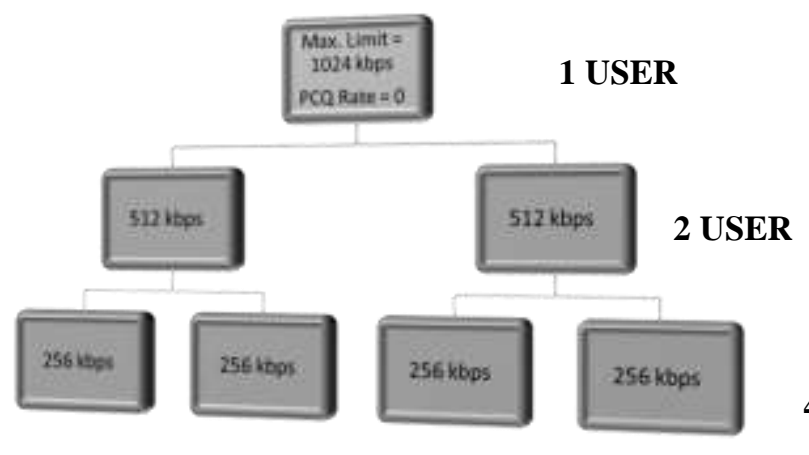

4 USER

Gambar 3. Skema $P C Q$

\section{Hotspot}

Hotspot adalah sebuah titik area dimana seseorang dapat terhubung dengan internet secara wireless melalui perangkat mobile selama masih berada dalam jangkauan sinyal access point titik hotspot tersebut. Hotspot biasa ditemukan pada beberapa titik lokasi seperti di pusat perbelanjaan, sekolah, universitas, cafe, hotel, rumah sakit, taman, perpustakaan, serta tempat umum lainnya.

\section{Voucher System}

Sebuah sistem yang melakukan fungsi pembuatan kode akses berupa username dan password user secara otomatis sehingga setiap user yang ingin terhubung kedalam jaringan dapat memasukan kode authentikasi yang tercetak pada voucher. Dengan sistem voucher, proses transaksi layanan komunikasi data internet menjadi jauh lebih mudah dan efisien. Kode yang dihasilkan oleh voucher sistem memudahkan pengelola jaringan dalam mengelola user karena setiap user akan langsung terhubung ke jaringan setelah login menggunakan kode akses yang diberikan tanpa harus menambahkan secara manual.

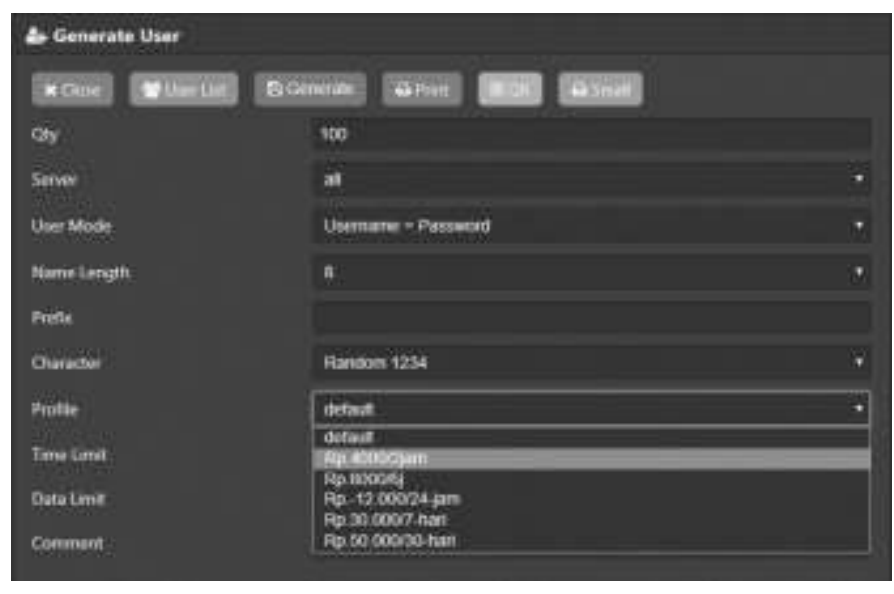

Gambar 4. Voucher System

\section{METODE PENELITIAN}

\section{A. Network Development Life Cycle}

Metode yang digunakan pada adalah metode Network Development Life Cycle (NDLC). Model NDLC terdiri atas beberapa tahapan diantaranya, Analysis, Design, Simulation, Implementation, Monitoring, serta Management. 


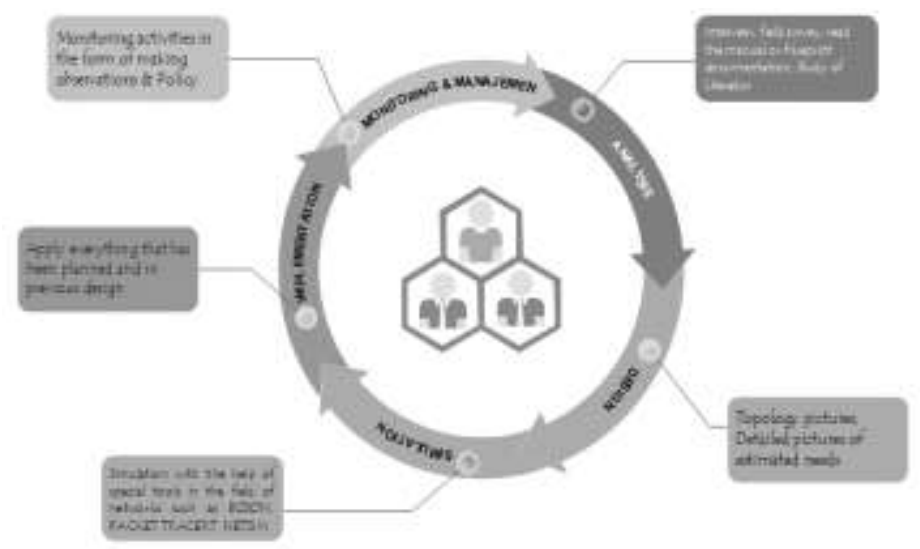

Gambar 5. Model Network Development Life Cycle[9]

\section{B. Tahapan Proses Pelaksanaan}

Pada tahap awal dilakukan analisis terhadap kebutuhan, masalah yang muncul, keinginan pengguna, serta topologi / analisis jaringan yang sudah ada saat ini. Wawancara melibatkan struktur manajemen dari atas hingga ke bawah untuk mendapatkan data yang real dan lengkap. Langkah selanjutnya berupa survei lapangan untuk melihat kondisi real sehingga faktor- faktor yang dapat berpotensi menurunan kualitas performa jaringan dapat diketahui.

Berdasarkan data dari tahap sebelumnya, langkah selanjutnya berupa pembuatan gambar desain topologi jaringan yang akan dibangun, hasil desain topologi kemudian akan disimulasikan menggunakan perangkat lunak simulasi jaringan untuk melihat sejauh mana kinerja serta keandalannya. Setelah itu kemudian dilakukan upaya penerapan topologi yang telah dirancang pada tahap sebelumnya untuk direalisasikan di lapangan. Kemudian yang terakhir berupa pemantauan serta pengelolaan terhadap infrastruktur jaringan yang telah dibangun.

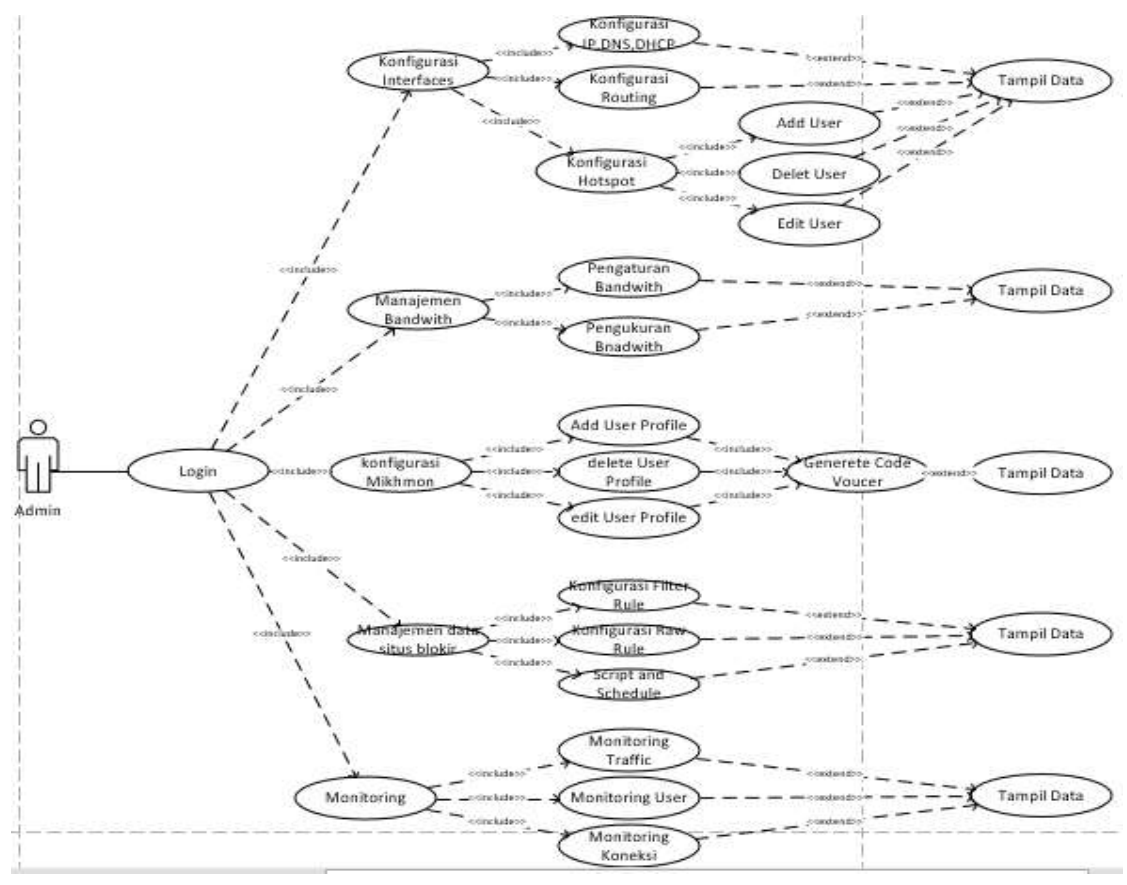

Gambar 6. Use case diagram manajemen bandwidth

\section{HASIL DAN PEMBAHASAN}

Pengujian terhadap kinerja jaringan menggunakan winbox sebagai aplikasi antarmuka serta the dude untuk melakukan aktifitas monitoring terhadap setiap user yang terhubung kedalam jaringan. Melalui aplikasi winbox kita dapat melakukan perubahan konfigurasi serta melihat hasil dari pengaturan yang telah dibuat sebelumnya pada layanan $P C Q$ yang berfungsi mengontrol penggunaan bandwidth internet. Pada gambar 7 , diperlihatkan data grafik yang diperoleh saat user melakukan aktifitas streaming youtube melalui aplikasi the dude. 


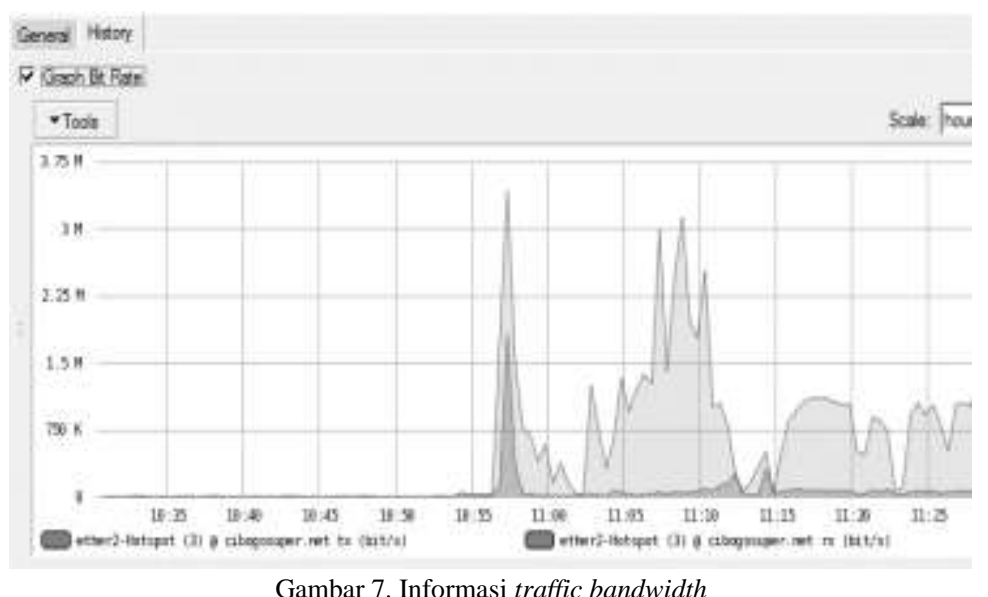

Pada tabel 1 di bawah, terlihat data hasil pengujian bandwidth untuk setiap paket data yaitu paket gold, silver dan bronze yang diperoleh melalui aplikasi mikhmon.

Tabel 1. Hasil pengujian

\begin{tabular}{|c|c|c|c|c|c|c|c|}
\hline \multirow{2}{*}{ User } & \multirow{2}{*}{ Paket } & \multirow{2}{*}{$\frac{\text { Max. Bandwidth }}{(\text { kbps })}$} & \multicolumn{3}{|c|}{ Layanan Paket } & \multicolumn{2}{|c|}{ Bandwidth rata-rata } \\
\hline & & & Browsing & Streaming & Game & PCQ Non-aktif & PCQ aktif \\
\hline Client_1 & SILVER & 512 & $v$ & $x$ & $\checkmark$ & 863 & 497 \\
\hline Client_2 & GOLD & 1024 & $v$ & $v$ & v & 937 & 934 \\
\hline Client_3 & GOLD & 1024 & $\checkmark$ & $\checkmark$ & $\checkmark$ & 853 & 972 \\
\hline Client_4 & BRONZE & 256 & $v$ & $x$ & $x$ & 794 & 213 \\
\hline Client_5 & GOLD & 1024 & v & $v$ & v & 896 & 987 \\
\hline Client_6 & SILVER & 512 & $v$ & $x$ & $v$ & 823 & 483 \\
\hline Client_7 & BRONZE & 256 & $v$ & $x$ & $x$ & 797 & 238 \\
\hline Client_8 & BRONZE & 256 & $v$ & $x$ & $x$ & 857 & 224 \\
\hline Client_9 & SILVER & 512 & $v$ & $x$ & $v$ & 871 & 496 \\
\hline Client_10 & SILVER & 512 & v & $\times$ & v & 912 & 478 \\
\hline Client_11 & GOLD & 1024 & $v$ & $v$ & v & 892 & 963 \\
\hline Client_12 & SILVER & 512 & v & $x$ & v & 864 & 486 \\
\hline
\end{tabular}




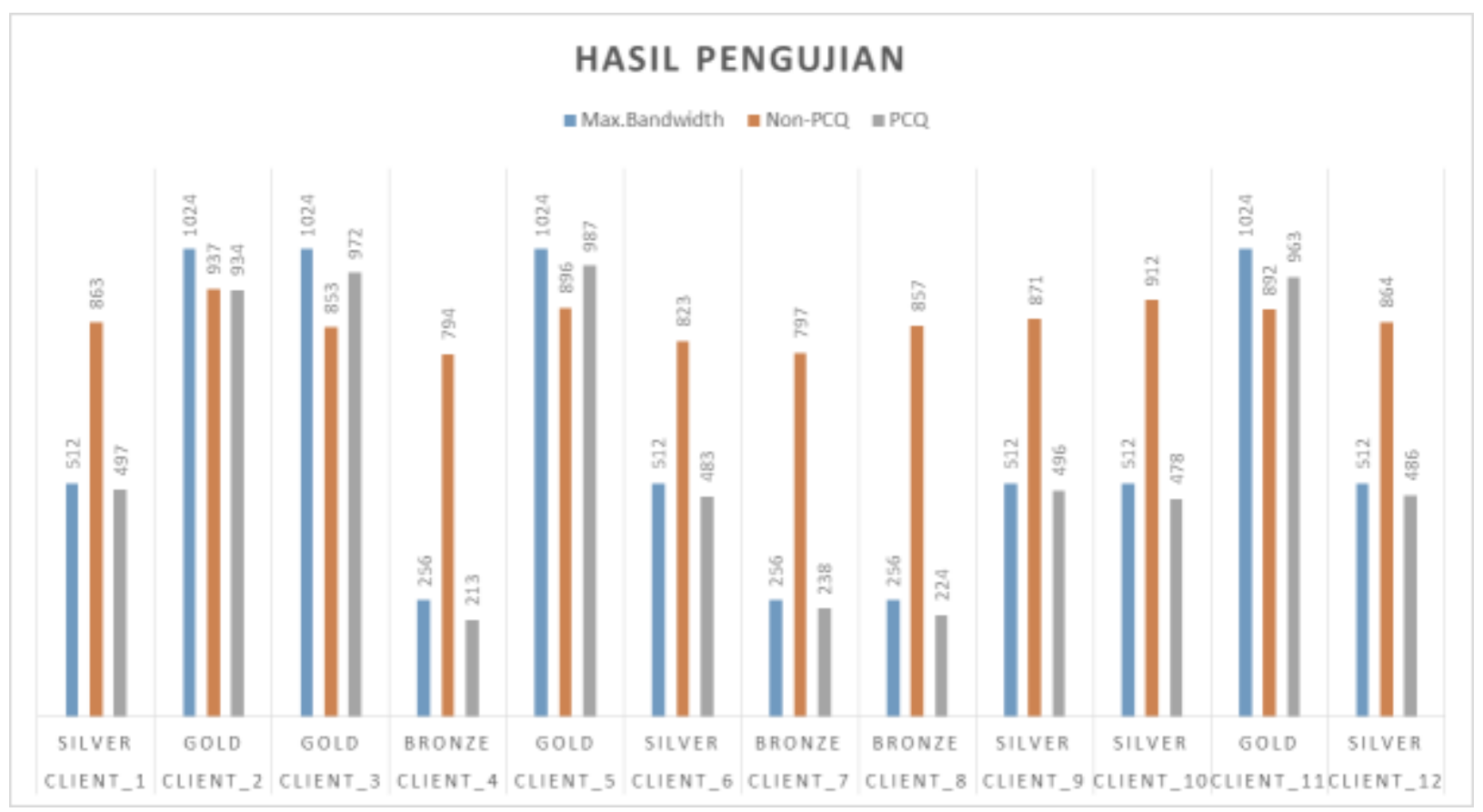

Gambar 8. Grafik informasi hasil pengujian

Berdasarkan grafik pada gambar 8 diatas, terlihat bahwa bandwidth yang dihasilkan dengan menggunakan metode $P C Q$ tidak akan melewati limitasi bandwidth yang ditetapkan untuk masing-masing paket. Sehingga dapat dibuktikan bahwa penggunaan metode PCQ akan membuat bandwidth terbagi secara merata. Sebelum menerapkan metode $P C Q$, setiap user meskipun berbeda paket data memperoleh besaran bandwidth yang hamper sama. Namun ketika $P C Q$ diterapkan, perbedaan kualitas layanan pada masing-masing paket dapat terlihat perbedaannya. Hal ini terlihat dari bandwidth yang diterima oleh setiap user nya, selain itu limitasi akses layanan untuk setiap paket berupa kegiatan browsing, streaming, dan gaming dapat bekerja secara optimal.

\section{KESIMPULAN}

Berdasarkan hasil pengujian, terlihat bahwa manajemen hotspot menggunakan sistem voucher dengan metode $P C Q$ dapat berjalan dengan baik. Segmentasi terhadap paket data yang dibuat terlihat dapat berjalan secara efektif. Kemudian dari tabel pengujian kita dapat melihat rata-rata bandwidth paket gold $962 \mathrm{kbps}$ dari $1024 \mathrm{kbps}$ atau sekitar 94,42\%, kemudian untuk paket silver rata-rata bandwidth $488 \mathrm{kbps}$ dari $512 \mathrm{kbps}$ atau sekitar 95,31\%, dan untuk paket bronze didapat nilai bandwidth rata-rata $225 \mathrm{kbps}$ dari $256 \mathrm{kbps}$ atau sekitar $87,8 \%$. Nilai yang diperoleh dapat dikatakan sangat baik, hal ini terlihat dari bandwidth yang diterima oleh setiap user nya. Selain itu limitasi akses layanan untuk setiap paket berupa kegiatan browsing, streaming, dan gaming dapat bekerja secara optimal.

\section{DAFTAR PUSTAKA}

[1] T. A. A. Sandi, E. K. Pratama, I. N. Leksono, and R. S. Anwar, "Implementasi Hotspot Login Menggunakan Capsman Mikrotik Pada Wilayah Yang Berbeda," J. Akrab Juara, vol. 4, no. 1, pp. 18-26, 2019.

[2] T. S. Fitria and A. Prihanto, "Implementasi Generate Voucher Hotspot Dengan Batasan Waktu (Time Based) Dan Kuota (Quota Based) Menggunakan User Manager Di Mikrotik,” J. Manaj. Inform., vol. 8, no. 2, 2018.

[3] G. D. Ramady, R. Hidayat, A. G. Mahardika, and W. Hidayat, "Optimizing Wireless Distribution System Network Infrastructure in Hybrid Topology using PCQ Method," in Journal of Physics: Conference Series, 2019, vol. 1424, no. 1, p. 12026.

[4] A. Kartini, “Membangun Jaringan Nirkabel (Hotspot Area) Dan Manajemen Hotspot Dengan'Antamedia Hotspot Manager'Sebagai Sarana Komersial Berbasis Wifi." J. Ilmu Komput, 2014.

[5] Y. I. Mukti, "Implementasi Jaringan Hotspot Kampus Menggunakan Router Mikrotik,” Indones. J. Comput. Sci., vol. 8, no. 2, pp. 130-138, 2019.

[6] R. Hidayat, N. Sri Lestari, A. Sujana, Herlina, and G. Devira Ramady, "Optimizing Branch Telephone Networks for Campus VoIP with Mobile Clients," in Journal of Physics: Conference Series, 2019, vol. 1175, no. 1.

[7] S. C. Abadi, "Sistem Pemantauan Kualitas Udara Menggunakan Cloud Application Bluemix," J. Elektra, vol. 4, no. 2, pp. 38-43, 2019.

[8] R. Hidayat, H. S. Winangun, N. S. Lestari, and G. D. Ramady, "Development of BTS Site Smart Key Based on Internet of Things," in 2019 International Seminar on Application for Technology of Information and Communication (iSemantic), 2019, pp. 507-512.

[9] M. T. Kurniawan, A. Nurfajar, O. Dwi, and U. Yunan, "Desain Topologi Jaringan Kabel Nirkabel PDII-LIPI dengan Cisco Three-Layered Hierarchical menggunakan NDLC,” ELKOMIKA J. Tek. Energi Elektr. Tek. Telekomun. Tek. Elektron., vol. 4, no. 1, p. $47,2016$. 